\title{
Missivas que constroem limites: projeto intelectual e projeto político nas cartas de Capistrano de Abreu ao Barão do Rio Branco (1886-1903)
}

Letters that construct limits: intellectual and political projects in the letters of Capistrano de Abreu to Barão do Rio Branco (1886-1903)

Daniel Mesquita Pereira*

Eduardo Ferraz Felippe ${ }^{* *}$

\section{Resumo}

A intenção deste artigo é analisar as cartas enviadas por Capistrano de Abreu ao Barão do Rio Branco, entre os anos de 1886 e 1903. O foco recai sobre as divergências em torno da noção de formação territorial, elemento fundamental para esses autores que estavam pensando a construção de uma narrativa histórica, em fins do século XIX e início do século XX. Posteriormente, problematiza-se a construção do ofício do historiador nas cartas de Capistrano de Abreu e sua distinção e proximidade frente às ponderações do Barão de Rio Branco.

Palavras-chave: correspondência; Capistrano de Abreu; Barão do Rio Branco; formação.

\section{Abstract}

The intention of this paper is to analyze the letters from Capistrano de Abreu to Barão do Rio Branco in the years between 1886 and 1903. The focus will be given to the divergences around the notion of territorial formation, a basic concept for these authors who were thinking about the construction of a historical narrative at the end of the $19^{\text {th }}$ and beginning of the $20^{\text {th }}$ century. Later, the question is the construction of the craft of the historian in the letters of Capistrano de Abreu and his distinction and proximity to the ideas of the Barão do Rio Branco.

Keywords: correspondence; Capistrano de Abreu; Barão do Rio Branco; formation.

\footnotetext{
* Doutor em História Social da Cultura (PUC-Rio), Professor do Departamento de História PUC/Rio. Rua Marquês de São Vicente, 225 - Prédio Cardeal Frings, $5^{\circ}$ and. Gávea. 22453-900 Rio de Janeiro - RJ - Brasil. danielpereir@gmail.com.

**Doutorando em História Social pela Universidade de São Paulo (USP), Mestre em História Social da Cultura (PUC/Rio). eferrazfelippe@oi.com.br.
} 
Foi com um pedido de desculpas pela intromissão que se iniciou uma das mais importantes trocas epistolares do historiador Capistrano de Abreu: "Espero que V. Exa compreenderá e desculpará esta carta". ${ }^{1}$ O tratamento respeitoso se referia ao então conselheiro, e posteriormente barão, José Maria da Silva Paranhos, aquele que iria tornar-se uma das figuras mais expressivas, no plano político, da Primeira República no Brasil: o Barão do Rio Branco. Aproximados pelo amigo em comum Vale Cabral, esses dois intelectuais profundamente preocupados com questões acerca da escrita da história e dos rumos políticos da nação no final do século XIX entabularam um diálogo distante, porém intenso, através das missivas.

Apesar da separação física, ou talvez por esse limite e imposição, foi diante da correspondência que os remetentes expuseram e alimentaram a expectativa de resposta acerca de suas questões, inquietudes e projetos políticos diferenciados. Nesses termos, a correspondência propiciou certo tipo de presentificação, um mostrar-se orientado para um outro determinado, antes do momento da escrita, gerando uma presença imediata que se assemelha a um exercício de dar-se a ver. Diferentes escrituras de si, compostas diante de olhos não presentes, mas materializados como presença no ato da escrita; uma afetação mútua, proporcionada pela troca epistolar entre os missivistas, fundada no conhecimento dialógico. ${ }^{2}$ Entretanto, uma lacuna documental impõe limites sérios à análise da troca epistolar aqui examinada: não foram guardadas, por Capistrano de Abreu, as cartas enviadas pelo Barão. Dessa forma, temos acesso apenas às cartas escritas por Capistrano de Abreu e, conseqüentemente, às considerações deste autor tanto sobre a construção dessa amizade, quanto referentes aos estudos históricos. Não obstante, seu limite pode ser sua riqueza: a partir de um universo restrito e delimitado, é possível analisar a constituição da identidade de um outro como destinatário, através das imagens que o autor das cartas descreve, num jogo composto por palavras, registros, lacunas e silêncios.

Nesse caso, este artigo comporta uma estratégia que põe em foco algumas questões. Em um primeiro instante, ele permite conhecer melhor as tramas do campo intelectual brasileiro do final do século XIX, bem como suas articulações com autores estrangeiros, identificando alguns que serviam de base para as suas elaborações teóricas, assim como para a fundamentação de suas pesquisas. A figura do Barão do Rio Branco e as condições em que atuou como intelectual, visualizadas principalmente através do tratamento e das solicitações geradas por Capistrano de Abreu, oferecem pistas para entender como eram debatidas as questões acerca da formação territorial do Brasil 
e projetos políticos para a nação, como também a importância do conhecimento histórico nessas querelas. Em um segundo instante, mas intimamente associado ao primeiro, o estudo dessa escrita epistolar é uma forma de recuperar as relações existentes entre a moderna produção dos estudos históricos e o caráter de legitimação que possuíam nas decisões tomadas com relação aos limites do território. ${ }^{3}$ Esta troca epistolar, em específico, possuía como tema central a constituição dos limites do território nacional, uma questão para grande parte da intelectualidade, em fins do século XIX e início do século XX, e elemento fundamental a ser considerado na constituição do Brasil enquanto nação soberana.

Além disso, possibilita compreender o movimento de formação do próprio Capistrano de Abreu enquanto historiador moderno, ${ }^{4}$ um intelectual que se caracterizava por conseguir manipular determinado método capaz de conferir legitimidade ao conhecimento histórico, e do próprio Barão do Rio Branco como intelectual que gradualmente alçava postos cada vez mais altos dentro da diplomacia. Uma troca de cartas menos delineada pela amizade ou por uma relação afetuosa, mas que permite notar como as discussões acerca do conhecimento histórico foram capazes de unir dois intelectuais de perfis tão distintos, aproximados pelo debate acerca dos elementos capazes de possibilitar a independência, não mais política, mas econômica e intelectual do Brasil.

\section{O POLÍGRAFO E O JOGADOR DE XADREZ: A CARTOGRAFIA das Cartas Capistrano-Barão do Rio Branco}

Como produto da interação entre remetente e destinatário, a carta é um objeto que permite obter informações de ambas as partes. Uma vez escrita, a carta já não é mais de quem a escreve, e, sim, de quem a recebe; uma vez recebida, a carta guarda a possibilidade de investigar o destinatário, e já não mais se concentrar unicamente no autor do escrito. Nesse sentido, analisar as cartas enviadas por Capistrano ao Barão do Rio Branco propicia o estudo não somente do conteúdo informativo das cartas, caracterizado principalmente pelas divergentes opiniões acerca da política externa e da perspectiva interpretativa da ocupação do território. Para além disso, das cartas de Capistrano surge um José Maria da Silva Paranhos ainda em período de formação, o que propicia a observação da ascensão de cargos que o inicialmente "conselheiro" 
galgou até chegar a "Barão", conforme o tratamento respeitoso utilizado por Capistrano de Abreu para se referir ao amigo.

A troca epistolar entre Capistrano e o Barão do Rio Branco foi uma das principais de sua correspondência e se iniciou em 1886, quando José Maria da Silva Paranhos estava na Europa tratando de assuntos relativos à diplomacia brasileira. Ao se estabelecer na Inglaterra, como cônsul em Liverpool, viveu em relativa obscuridade e desenvolveu sua paixão pelo exame de mapas antigos e documentos históricos. Neste seu "longo estágio no estrangeiro" (18761902), conforme a afirmação de Rubens Ricupero, acumulou a experiência de viver em um país que era a encarnação do capitalismo industrial, do liberalismo político e do sistema parlamentar de governo. Apesar de monarquista, foi o governo jacobino de Floriano que, primeiramente, lhe confiou a delegação das Misiones (1895); o que o habilitou a disputar outras querelas acerca dos limites do território, como a questão do Amapá (1898-1900) e a mais difícil, a questão do Acre (1912). Desde o período em que esteve em Liverpool até a obtenção de vitórias nessas querelas diplomáticas, José Maria da Silva Paranhos conseguiu construir uma ampla reputação e um círculo intelectual que tinha em sua figura o epicentro de discussões e leituras. ${ }^{5}$

De outro modo, Capistrano de Abreu, como foi caracterizado por muitos de seus biógrafos, era o antípoda do indivíduo sociável. Uma auto-representação que investiu em seu caráter de intelectual recluso, na tendência ao isolamento e na vida dedicada ao solitário trabalho socialmente útil, em outras palavras, uma estratégia de auto-representação que investiu em certa acepção do trabalho intelectual e que foi corroborada pelo enquadramento da memória desse intelectual. ${ }^{6}$ Entretanto, além desse suposto isolamento físico, o autor de Capítulos de História Colonial estabeleceu uma forma própria de sociabilidade que se definiu pelas práticas e estratégias que desenvolveu para o seu convívio intelectual, principalmente através das cartas. A análise mais atenta de sua correspondência sugere que a imagem de homem recluso contrasta com a volumosa correspondência tecida com outros intelectuais, de ambiência tanto nacional quanto internacional.

O perfil intelectual de Capistrano de Abreu demarca algumas inserções comuns à intelectualidade brasileira, em fins do século XIX e início do século XX. Vários de seus contemporâneos, como ele, escreviam para os jornais, palco das polêmicas do fim do século XIX. ${ }^{7}$ Contudo, apresentava a sua inserção como pertencente a um campo de saber específico: os estudos históricos. Um campo, por sua vez, permeado por estudos que atualmente são considerados saberes autônomos - como a geografia, por exemplo - visto que não havia 
distinção disciplinar rígida capaz de delimitar fronteiras e construir barreiras perante outros saberes. ${ }^{8}$ Uma delimitação que somente seria construída, como analisa Ângela de Castro Gomes, posteriormente, durante o Estado Novo, quando foi desenvolvida uma política cultural dedicada à construção de uma "cultura histórica" que concedia lugar de destaque à história como forma de conhecimento social. ${ }^{9} \mathrm{O}$ autor de Capítulos de História Colonial viveu em um momento no qual a estratégica ordenação dos campos do saber, empreendida pela política cultural do Estado Novo, ainda não havia sido sedimentada e os estudos históricos estavam direcionados a atividades particulares, nas quais a palavra "historiador" poderia comportar uma ampla e diversificada possibilidade de leituras.

Nesses tempos, Capistrano já era um historiador conhecido no meio intelectual de que participava. Havia sido funcionário da Biblioteca Nacional entre 1879 e 1883, período em que resolveu enveredar de vez pelos estudos históricos, conhecendo documentos, fazendo transcrições e tomando contato com catálogos de todo o mundo. No início da correspondência com o Barão do Rio Branco, era professor do colégio D. Pedro II, após ter conseguido o cargo com a tese sobre o Descobrimento do Brasil, que depois seria publicada sob mesmo nome pelo autor. Nessa ocasião, ainda não havia escrito o artigo Caminhos Antigos e Povoamento do Brasil nem o livro Capítulos de História Colonial, que o consagraria definitivamente como um dos mais importantes historiadores do Brasil. Além disso, Capistrano não havia sofrido, ainda, as principais perdas familiares que eternizariam sua imagem como velho taciturno e melancólico. Em outras palavras, é possível capturar nessa troca epistolar um Capistrano em "formação", ligado principalmente à divulgação dos documentos que dão base à elaboração de seu projeto intelectual: a escrita de uma história do Brasil.

O ritmo da correspondência trocada por dezessete anos entre dois intelectuais se inicia com uma troca intensa de missivas. Desta forma, diferentemente de outras trocas epistolares, não houve um estabelecimento tímido de um contato inicial que, posteriormente, ganhou maior adensamento. Conforme o volume de cartas disponível para consulta, há um ritmo intenso e constante de envio de missivas desde o estabelecimento do contato inicial. Nele fica inteiramente caracterizado que a correspondência iria cumprir o papel fundamental de espaço de troca intelectual entre eles, estabelecendo-se o perfil básico de cada missivista: de um lado, um importante diplomata que cada vez mais ganhava destaque na ambiência política brasileira; de outro, o "admirador muito grato" Capistrano de Abreu - código utilizado em grande 
parte dos fechamentos das cartas - , que se beneficiava dos documentos enviados para as suas pesquisas históricas.

Apesar de ter durado mais de quinze anos, a distância existente entre os dois missivistas permaneceu desde a primeira até a última carta. Ela se verifica na expressa admiração do então historiador da Biblioteca Nacional, Capistrano de Abreu, pelo "Exmo", inicialmente, "conselheiro", e, posteriormente, "Barão do Rio Branco". Sempre pautada por "Mestre e amigo", entre ambos foi tecida uma relação que se caracterizou, principalmente, por certa distância que apresentava de maneira muito clara a diferença entre as posições ocupadas pelos dois intelectuais no círculo intelectual do Império e, posteriormente, da República. Uma troca epistolar que apresenta singularidade dentro do heterogêneo conjunto de sua correspondência e que difere de trocas que tinham o afeto como principal característica, como, por exemplo, a troca epistolar com João Lúcio Azevedo. ${ }^{10}$

Cabe considerar que a associação entre a diplomacia e os estudos históricos era considerada como "natural" e proveitosa por parte do ambiente político do Itamaraty. Na realidade, a história e a geografia eram instrumentos de legitimação de escolhas realizadas no âmbito político por parte daqueles que estavam pensando, discutindo e decidindo acerca dos limites e fronteiras do Estado-nação. Um lugar de legitimidade, capaz de pacificar discussões e querelas políticas tensas no presente. Entretanto, esse "lugar de sociabilidade"11 que a correspondência propicia foi perpassado, no caso desta troca epistolar, por temas variados, como envio de documentos, questões acerca dos limites do território e tensões referentes à passagem do final do Império para o início da República. Sobre este último tema, as cartas de Capistrano são ricas em apontamentos acerca das angústias do jovem autor sobre os rumos da nação.

A principal imagem desses relatos está em uma carta enviada ao Barão de Rio Branco, datada de 25 de janeiro de 1890, na qual Capistrano analisa como ocorreu a queda do Império:

Recebi a sua última carta no dia 15 de Novembro! Vinha do campo de Santana impressionado, como pode imaginar, depois de ter visto uma revolução. E que revolução! Só há uma palavra que reproduz o que vi: empilhamento. Levantou-se uma brigada, chegaram os batalhões um a um, sem coesão, sem atração, sem resolução e foram-se encostando um a um como peixe na salga. Quando não havia mais batalhão ausente ou duvidoso, proclamou-se a República, sem que ninguém reagisse, sem que ninguém protestasse. No ponto em que as coisas estavam, era a única solução razoável. Antes uma Deodorada do que uma Saldanhada. Todo 
o Brasil aderiu; apenas em Pernambuco José Mariano levantou um grito separatista que não ecoou. Digam o que quiserem, a República é hoje pátria unida; a restauração seria secessão. (CA-RB 25.01.1890)

Conformado, Abreu narrou a cena da queda do Império ao Barão do Rio Branco. A substituição de revolução por "empilhamento" dota as suas ponderações de profunda apreensão, como se a mudança ocorrida significasse pouco, uma simples alteração superficial incapaz de alterar profundamente o momento em que vivia. Apesar de a unidade da pátria fechar a carta indicando um balanço positivo para o evento, o "empilhamento" deixa de significar uma pretensão de intencionalidade para as ações; a mudança de regime foi fruto de uma inevitabilidade histórica: o regime político posterior ganhou vida após o primeiro ter exaurido suas forças. O risco iminente era de que ocorresse a fragmentação do território, a perda de um legado deixado pela colonização portuguesa, assim como variável importante no jogo político das nações.

\section{UM TERRITÓRIO, DOIS PROJETOS}

A partir destas cartas, podemos avaliar como havia entre os dois intelectuais interesses acerca do território nacional e de sua valorização como um dos elementos da herança da colonização portuguesa. Herança advinda do processo histórico, o território era, para ambos, um aspecto fundamental de diferenciação do brasileiro frente aos portugueses e ao conjunto das outras Nações. A dimensão territorial do Brasil era a demonstração de um princípio de força do Estado-nação, aquilo que o colocava como um dos territórios de maior extensão, um critério que lhe permitia estar entre as principais nações do mundo.

Para Capistrano, o território é componente essencial da "história íntima" - a sua particular concepção acerca da história nacional -, aquela que narra a lenta ocupação do território, a interiorização do povoamento e a formação da nação brasileira; um elemento que se inscreve como denominador comum entre os diversificados espaços e centros de povoamento - entre os cinco grupos etnográficos - conforme expresso em seus Capítulos de História Colonial. Na opinião do então jovem historiador cearense, o Brasil precisaria de duas histórias, uma interna e outra externa. A interna seria

Uma história íntima - [que] deve mostrar como aos poucos se foi formando a população, devassando o interior ligando entre si as diferentes partes do 
território, fundando indústrias, adquirindo hábitos, adaptando-se ao meio e constituindo por fim a nação. Esta história deve escrevê-la um brasileiro, e só daqui a quarenta anos será possível, quando estiverem reunidos os documentos, e as monografias tiverem esclarecido pontos ainda obscuros. ${ }^{12}$

Ambas seriam a expressão da especificidade do seu projeto intelectual, aquilo que singularizaria a sua contribuição para a compreensão da História do Brasil e demarcaria um novo rumo nas pesquisas que estavam ocorrendo, com a descoberta de novos documentos e temas. Entender como ocorreu gradualmente o povoamento do território possibilitava a Capistrano descortinar a trajetória histórica de um povo, "capado e recapado" por mais de quatro séculos, de uma história esquecida em razão do excessivo peso dado ao povoamento do litoral. Foi em missiva enviada ao Barão que Capistrano indicou a principal questão da história pátria: "o povoamento entre São Francisco e o Parnaíba” (CA-RB 09.04.1887).

Para o Barão do Rio Branco, as preocupações incidiam em outra esfera. Ele herdou, em aberto, uma série de questões sobre os limites do território brasileiro no Império. No início da República, o conjunto dessas questões constituía o problema prioritário da política externa brasileira, da mesma forma que tinham sido, anteriormente, o reconhecimento da Independência e o fim do tráfico de escravos no começo da monarquia. Ou seja, uma mudança de direcionamento e de foco de atenção, mas que expressava, ainda, o temor acerca da fragmentação em que poderia cair o Brasil, em fins do período imperial.

Três eixos principais sustentavam a política externa no período e formavam um todo integrado e coerente. Esses eixos eram a política territorial, as relações assimétricas de poder - tecidas com as grandes nações européias e os Estados Unidos da América - e as relações de relativa simetria com os vizinhos da América do Sul. ${ }^{13} \mathrm{O}$ território era um dos pilares de sustentação de uma política externa pautada, principalmente, por critérios histórico-geográficos. A definição do perfil territorial e do mapa em cujo interior irá se exercer a soberania é, para qualquer nação, uma espécie de condição para o desenvolvimento de uma política externa. No momento da proclamação da República, duas fronteiras, apenas, haviam sido definidas: com o Paraguai e com o Uruguai. O território era a base da expressão de poder das nações, um importante pré-requisito.

Nesse sentido, as preocupações de Capistrano de Abreu e do Barão do Rio Branco convergem. O historiador acompanhou de perto as vitórias diplo- 
máticas do Barão e, numa carta a ele enviada, comentava o triunfo na questão de limites com a Argentina: "Seus triunfos são da pátria e portanto meus. Se, em sua missão, algum dia lembrou-se de mim, há de ter sentido que estava a seu lado, quando pugnava por nossos direitos, que depois da vitória dava-lhe um abraço apertado, que agora repito..." (CA-RB 22.06.1895).

Mesmo com ênfases diferentes - pois, enquanto Capistrano tende a olhar para a formação de uma "pátria interior" baseada na ligação física entre as estradas do povoamento do sertão, ou nos caminhos antigos, o Barão tende a buscar soluções para a questão dos limites, definindo os contornos externos do mapa do Brasil - , as preocupações de ambos se aproximam no que diz respeito ao reconhecimento da ocupação portuguesa como base para legitimar os direitos do Brasil sobre territórios em disputa. Esse argumento, como se sabe, foi utilizado pelo Barão nas memórias que redigiu para as contendas diplomáticas com a França e a Inglaterra. Capistrano, por sua vez, como fica claro para o leitor dos Caminhos antigos e povoamento do Brasil, considera o território a partir da interação entre os homens e a natureza. Para tanto, utiliza o instrumental teórico da geografia.

Capistrano compreendeu que, graças ao lugar central que a natureza possui como referência para pensar o Brasil, necessitava buscar na geografia um instrumental científico para lidar com a questão. O encontro com Ratzel ${ }^{14}$ teve profundo impacto em sua compreensão do estudo da história, a partir da questão da relação entre a sociedade e as condições ambientais. Segundo Ratzel, cada localidade deve comungar das condições ambientes com que o espaço físico a dotou, e seu avanço ocorrerá a partir da intervenção consciente dos homens; as condições do meio não serão rigidamente determinantes, mas haverá sempre uma margem de manobra para todos os indivíduos de acordo com as possibilidades propiciadas pelo meio. Além desse aspecto, para a localização atual dos grupos dever-se-ia adicionar a investigação de sua mobilidade passada, buscando levantar suas áreas originárias e seus itinerários. Esse campo de investigação completar-se-ia com o estudo da difusão dos povos sobre o espaço.

A "ação incorporada e inteligente" sobre o meio físico torna possível que os homens desenvolvam relações sociais de certa autonomia frente às injunções desse meio. Capistrano, seguindo Ratzel, chamou esses atores autônomos de povo civilizado. Dessa maneira, assume a idéia de que o nomadismo seria oposto à sedentarização, tida como indício de civilização. Esse entendimento tem raízes profundas, estando presente, segundo Anthony Pagden, em muitos viajantes europeus ao Novo Mundo, uma vez que a cultura européia sendo 
fundamentada desde a Antiguidade na noção de oikos e, portanto, sendo ela constituída a partir da base organizativa da casa e na valorização da cidade, contrapõe à idéia de civilização o nomadismo. ${ }^{15} \mathrm{O}$ movimento e a não-fixação territorial são associados à idéia de desordem, assim como para Capistrano.

Nesse compasso, a valorização do tipo do "conquistador" frente ao "bandeirante" nos Capítulos, como em Caminhos, ajuda na compreensão dessas afirmações. No início dos Caminhos antigos e povoamento do Brasil, Capistrano recorta seu objeto de estudo em função da demonstração de seu argumento: uma lenta e gradual vitória de "conquistadores" no sentido de povoar a terra apesar dos obstáculos naturais, ou, de sua interação com a natureza, o que aponta para a formação de diferentes modos de vida, hábitos, costumes, consoante a própria diversidade ambiental nas diferentes regiões do território. Nesse estudo, por exemplo, são deixadas de lado as capitanias de João de Barros, Fernão Álvares, Ayres da Cunha e Antônio de Barros, pois estas "passaram sem deixar sinais".

Nas capitanias situadas além do cabo de São Roque, entretanto, a natureza se tornou um obstáculo cuja superação exigiu mais tempo e acentuou os esforços dos homens para implantar a civilização: "A ponta arenosa e sáfia, descoberta em agosto de 1501, resistiu à ação colonizadora tão rijamente como o Bojador e o Tormentório aos que procuravam os caminhos das Índias. A ocupação... só vingou no século XVII" ${ }^{16}$ Aqui está suposta a idéia de que a variável espacial pouco representa sem uma correspondência com a variável temporal. A confluência das duas variáveis significa que o espaço interessará mais onde tiver sofrido intervenção da ação civilizadora, ou onde quer que a história, ou o tempo como força motriz, tenha deixado sua marca.

Caminhos antigos tem como fio condutor a demonstração da contigüidade territorial do Brasil, mas uma contigüidade construída e consolidada pela ação humana a partir de "pontos apartados" do território. Entre seus agentes principais estavam os conquistadores, que fixaram raízes e contribuíram de fato para o povoamento. Essa mesma argumentação, que contrasta esse tipo social com o do bandeirante, seria recuperada nos Capítulos de História Colonial, em que o autor não nega ao bandeirante, entretanto, a possibilidade de se converter em "conquistador" e "mineiro":

Ao assunto que estudamos não pertencem as bandeiras, por motivos óbvios. Concorreram antes para despovoar do que para povoar nossa terra, trazendo índios dos lugares que habitavam, causando sua morte em grande número, ora nos assaltos às aldeias ealdeamentos, ora com os maus tratos infligidos em viagem, ora, terminadas 
estas, pelas epidemias fatais e constantes, aqui e alhures apenas os silvícolas entram em contato com os civilizados. Acresce que os bandeirantes iam e tornavam, não se fixavam nunca nos territórios percorridos... A atenção que não cabe aos bandeirantes reclamam-na de passagem os conquistadores, homens audazes, contratados pelos poderes públicos para pacificar certas regiões em que os naturais apresentavam mais rija resistência... geralmente não tornavam à pátria e deixaram sinais de sua passagem e herdeiros de seu sangue... (Abreu, 1977, p.37)

A longa citação merece destaque não somente por distinguir claramente conquistadores de bandeirantes, mas também por assinalar as ligações entre os núcleos de povoamento do interior que são importantes peças para a demonstração que o autor elabora da contigüidade territorial do Brasil. Assinalam também como agente central da expansão o povoamento para dentro dos limites da "ilha-Brasil", ${ }^{17}$ o conquistador e sua descendência, sugerindo que a ocupação dos sertões se deveu a alguns grupos familiares cuja lembrança se conserva e tantos outros esquecidos.

Apesar de considerar o tema do território como fundamental para o conhecimento da história brasileira e, assim como Capistrano, pensá-lo como uma herança da colonização portuguesa, a ênfase da história escrita pelo Barão do Rio Branco está na ocupação do litoral e expressa bem o que Capistrano de Abreu denominou "história externa", ou seja, a de Portugal e da relação do Império com as possessões ultramarinas. $\mathrm{O}$ texto de história do livro $O$ Brasil. 1889, organizado por E. Lavasseur, foi escrito pelo Barão do Rio Branco e, ao que parece, foi composto a partir de excertos de sua História do Brasil publicada em francês, sobre a qual Capistrano se refere de maneira elogiosa. "Ia terminar sem lhe dar os parabéns pela sua História do Brasil. É esplêndida, e quanto aprendi nela! Veio-me a idéia de traduzi-la, acrescentando-lhe alguns capítulos e notas" (CA-RB 25.10.1890). Possivelmente, os capítulos que Capistrano pretendia acrescentar seriam relativos a questões do povoamento e do sertão, temas ausentes do texto sobre História do Brasil presente na referida coletânea.

Enquanto esse texto alinhavado pelo Barão possuía como similaridade ao texto de Capistrano o fato de iniciar com uma descrição dos aspectos físicos do território do Brasil e de sua diversidade de elementos que compunham a fauna e a flora, possuía, também, uma semelhança maior ainda com o texto de Varnhagen. Essa semelhança se apresentava pelo fato de que a História do Brasil, conforme o autor enunciou, se iniciou com a chegada dos portugueses que trouxeram a civilização; além do que em nenhum momento tratava do povoamento do interior do Brasil, nem do sertão. Para o Barão do Rio Branco, o que estava em questão era a disputa pelas fronteiras. Conhecer a história 
era fundamental, pois ela seria peça importante no jogo de xadrez em que se instauraram as diversificadas negociações acerca das fronteiras com as nações vizinhas, como também, na constituição dos argumentos que permitiram um diferenciado alinhamento na política internacional e na participação do Brasil no conjunto das nações.

Conforme afirma Gustavo Sénéchal Júnior, por mais que se reconheçam os aspectos pragmáticos da ação do Barão do Rio Branco na condução dos negócios estrangeiros do Brasil, não se pode ignorar a existência de pelo menos duas matrizes filosóficas que orientaram a sua ação, dois paradigmas distintos que se aplicam para explicar a sua política externa. Ao ponderar, nesse estudo, que há uma tensão entre os elementos realistas e racionalistas, o autor aguça a presença de elementos grotianos na diplomacia do Barão do Rio Branco, cuja expressão mais evidente é a tentativa de justificar a ação exterior em determinadas áreas por meio de normas estabelecidas pela comunidade internacional, além de defender o princípio de igualdade jurídica dos Estados. Por realismo o autor considera a oposição de vontades e o conflito como a realidade ontológica do mundo, onde os princípios morais jamais serão plenamente realizados, mas devem ser buscados por meio de acordos de equilíbrio de poder temporários. A presença de elementos grotianos é a defesa do princípio basilar da igualdade jurídica, apesar da ampla zona de confronto existente perpetuamente entre as diferentes nações; ou seja, um princípio racionalista que equilibra o pragmatismo utilizado no que tange à resolução dos conflitos, principalmente com relação às fronteiras territoriais, amplamente utilizado pelo Barão do Rio Branco. ${ }^{18}$

O Barão era um arguto jogador que soube observar bem a diferença de tratamento que mereciam as diversificadas questões diplomáticas em que estava inserido o Brasil. Segundo Rubens Ricupero, ele soube notar que a natureza das relações do Brasil com as potências européias divergia profundamente das que eram mantidas no Prata com os demais vizinhos da América do Sul, instaurando um novo regime de negociações com esses países. O primeiro tipo de negociação relevava o eixo de desigualdade e assimetria, pois havia um diferencial de poder que inferiorizava o Brasil em face desses países dominantes em tal ordem. Já no Prata, a essência do relacionamento se ajustava melhor ao eixo da relativa simetria. ${ }^{19}$

Nas discussões sobre as relações internacionais brasileiras na época do Barão, um tópico ficou bastante conhecido: a mudança do eixo diplomático de Londres para Washington. Esse foi o principal ponto de tensão entre as ponderações do Barão e de Capistrano. No caso, para entender melhor a crítica de Capistrano à aproximação com os Estados Unidos, cabe recorrer a outra troca epistolar, a tecida com Domício da Gama. Capistrano não fez ne- 
nhuma crítica ao projeto de aproximação com os Estados Unidos pelo Barão diretamente a ele, mas em carta a esse outro missivista, escreveu:

Em diplomacia somos associados, não somos aliados; temos de formar ao lado dos Estados Unidos, entregar nosso voto a Wilson. Não creio na amizade dos Estados Unidos, filho espúrio de Salvador de Mendonça, criado e chocado pelo Barão, pelo Nabuco, por V.[ocê], talvez por Assis Brasil, que já tem a visão menos turva... o manual do Itamarati deve ser a Ilusão americana. Tem um? Deve ter, mas é o livro de um homem. ${ }^{20}$

Como forma de questionar essa postura intelectual e seu direcionamento político, Capistrano utilizava a imagem de outro intelectual como exemplo de retidão: Eduardo Prado. Em seu A ilusão americana, esse autor afirmava a identidade nacional pela negação do exemplo norte-americano, apresentando a contraposição entre duas Américas: a América do espírito e a América da força, reafirmando a filiação do Brasil à civilização européia e reforçando a especificidade do Brasil frente às demais nações da América Latina. $\mathrm{O}$ intuito explícito de Eduardo Prado, ao estabelecer uma filiação européia para o Brasil, era criticar a política externa da República brasileira. O que o autor via na República era o desenfreado apetite individual que corrompia todos os valores, o particularismo contraposto ao domínio público, as soluções individuais em prejuízo do bem geral. O particularismo criava uma situação de corrupção na qual o governo de uns sobre os outros levaria à decadência. A idéia que permeia o pensamento de Eduardo Prado seria a de que o país praticava uma opção política deslocada, por imitação e moda, e que o motor de tal prática era o motor desfibrado do brasileiro. Em seu livro, a noção de cópia como aquilo que permeia o pensamento nacional entra na composição de sua crítica à aproximação do Brasil ao modelo norte-americano: "Copiemos, copiemos, pensam os insensatos, copiemos, e seremos grandes! Deveríamos antes dizer: sejamos nós mesmos, sejamos o que somos, e só assim seremos alguma coisa" ${ }^{21}$

Entretanto, se o projeto político do Barão do Rio Branco para a integração do Brasil no concerto político das nações destoava completamente da perspectiva de Capistrano de Abreu, havia um ponto de aproximação que nos interessa: a maneira como lidavam com a construção do conhecimento histórico. Através da troca epistolar com Capistrano de Abreu, houve a valorização, por parte do Barão do Rio Branco, de um conjunto de procedimentos e práticas que possibilitaram o uso do passado enquanto forma de dirimir questões políticas e associar significação ao presente. 


\section{Provas, documentos, testemunhas: OFÍCIO DO HISTORIADOR NA CORRESPONDÊNCIA}

Além destas questões relacionadas ao território e ao âmbito político, outro aspecto aproximava os dois autores. Cada pesquisa empreendida em particular por algum intelectual se fundamentava na crítica histórica enquanto elemento primordial em sua construção do conhecimento sobre o passado. Ambos partilhavam de uma característica semelhante: aquilo que Anthony Grafton designava como o "gosto pelo arquivo" característico da disciplina histórica do século XIX.22 Isso era objeto de verdadeiro regozijo por parte de Capistrano:

Tenho lido suas Efemérides no Jornal do Brasil e as apreciado devidamente. Pela primeira aparece neste gênero trabalho sério e fundado nas fontes. Abreu e Lima, Perdigão Malheiro não tinham idéia clara da crítica histórica. Menos ainda José de Vasconcelos. Teixeira de Melo fez em grande parte apenas simples compilação; quando Cabral e eu quisemos ajudá-lo, já era tarde. (CA-RB 05.08.1891)

A carta explicita bem a necessidade de que a seriedade do trabalho viesse associada à fundamentação nas fontes, ponto de aproximação entre Capistrano de Abreu e o Barão do Rio Branco. Conforme apontam muitos autores, Capistrano possui um lugar realmente único no conjunto da historiografia brasileira, por ter sido o responsável pela difusão do método da crítica histórica. A escrita da história deveria, necessariamente, estar atrelada a certo tipo de metodologia baseada na utilização de fontes e testemunhas documentais. Além disso, a história não mais seria a expressão de uma narrativa homogênea em que os fatos estivessem expressos a partir de uma ordenação cronológica, mas condensados em uma narrativa pautada em determinado enredo. ${ }^{23}$

A reformulação operada por Ranke no campo metodológico era conhecida do historiador, que cobrava de seus amigos mais próximos e de seus contemporâneos uma prática condizente com os avanços da disciplina. Conforme uma carta enviada ao amigo Guilherme Studart: "Por que... motivo te insurges contra uma obrigação a que se sujeitam todos os historiadores, principalmente desde que, com os estudos arquivais, com a criação da crítica histórica, com a crítica das fontes criada por Leopold von Ranke, foi renovada a fisionomia da História?". ${ }^{24}$ Uma prática que o próprio Capistrano utilizava desde o texto da armada de D. Nuno Manuel e que aparece em seu texto Descobrimento do Brasil, inicialmente tese para o concurso do colégio D. Pedro II. 
A crítica histórica, dessa maneira, definia as condições de enunciação do discurso sobre o passado. O historiador, agora munido de um conjunto de regras e procedimentos, era aquele que possuía legitimidade acerca do que deveria e poderia ser dito acerca do passado. Ele seria o responsável pelo controle de uma operação historiográfica, nos termos do trabalho clássico de Michel de Certeau, que definiria aquele conjunto de eventos que poderiam ser enquadrados como história. ${ }^{25}$ Com isso, provas, documentos e testemunhos caracterizavam os principais elementos configuradores de uma escrita da história no final do século XIX, apoiada no método histórico.

Para que isso ocorresse, era necessária a existência de um procedimento metódico capaz de transformar em "documentos" - após um processo de seleção e reunião - a transcrição de manuscritos e, a partir daí, procurar construir um "arquivo" que pudesse servir ao desejo de escrever a história do Brasil. Nestes termos, certos textos teriam seus estatutos modificados e, após sofrerem tal mudança, passariam a ser configurados dentro de uma coleção documental.

O que se tem, a partir da definição de arquivo, é o estabelecimento de um gesto fundador na operação histórica. Neste caso, o arquivo da história pátria define a condição de possibilidade do que pode ser dito acerca dessa história, ou seja, define contornos e limites para o surgimento de um diferenciado padrão narrativo, no caso de Capistrano de Abreu. Como bem caracteriza Michel Foucault em sua definição de arquivo: "arquivo é, de início, a lei do que pode ser dito, o sistema que rege o aparecimento de enunciados como acontecimentos singulares". O arquivo tem uma função modelar e precisa, pois ele é o que evita o nascimento de uma multidão amorfa, gerando o aparecimento de figuras distintas pautadas em uma determinada enunciação. Em outras palavras, quando Foucault define o arquivo como condição de possibilidade daquilo que pode ser dito, deve-se pensar na probabilidade de um acontecimento tornar-se um enunciado: "o arquivo é o que, na raiz mesma de seu enunciado-acontecimento ... define desde o início o sistema de sua enunciabilidade". ${ }^{26}$

Para a montagem de um arquivo da história pátria, era preciso ter contato com os manuscritos. Em razão das inúmeras viagens realizadas pelo Barão do Rio Branco, Capistrano solicitava ao seu correspondente, com freqüência, a aquisição de diversificados manuscritos a serem transcritos e que poderiam vir a compor um acervo documental necessário para escrever uma história pátria. $\mathrm{O}$ historiador cearense pretendia suprir as inúmeras lacunas existentes nas narrativas acerca da História do Brasil, como fica evidente neste trecho de uma das cartas ao Barão: 
Quanto a Colombo, não sei se fui bastante claro na carta que me referi ao processo. Quero apenas os quesitos relativos a Vicente Pinzón, a Diego de Lepe e Mendonça que são os únicos interessantes para a nossa história. Desejaria também, entre parênteses, notícias de um ms. relativo acerca do Brasil, escrito cerca de 1580 por João Batista Gessi. É citado por Jimenes de la Espada em um número da Sociedade de Geografia. (CA-RB 13.06.1888)

A solicitação de documentos foi uma constante ao longo dos mais de quinze anos de troca epistolar. Esses documentos seriam o alicerce de uma forma moderna de construção do conhecimento histórico, pautada em documentos e provas; por isso, ter contato com eles era uma tarefa primária para que pudesse ocorrer a escrita da história. Nesse sentido, outra tarefa importante do historiador se referia à publicação dos documentos. Graças ao argumento de legitimidade que o seu uso garantia, seria fundamental que tais documentos fossem tornados públicos para que o conhecimento da história pátria pudesse avançar. Essa solicitação aparece, por exemplo, em carta de 20 de abril de 1888, quando afirma: "Por que V. Exa não se resolve a fazer uma edição preparatória em nossa coleção? Ficaria o público desde logo senhor dos principais resultados" (CA-RB 20.04.1888). A edição com documentos era uma importante via de divulgação da produção historiográfica. Além disso, demarcava com clareza o debate existente nas fronteiras entre o público e o privado, que caracterizam o pertencimento desses documentos a determinadas instituições. Neste caso, a capacidade de dotar de autoridade um relato histórico, possibilitada pela documentação, é o que a torna tão valiosa para todos aqueles que se debruçavam sobre ela, sejam diplomatas ou historiadores.

As solicitações de Capistrano acerca da publicação de documentos eram direcionadas não somente ao Barão do Rio Branco, mas também a instituições, como a Biblioteca Nacional, por exemplo. Referindo-se às relações com o diretor daquela instituição Saldanha da Gama, em carta de fevereiro de 1887, Capistrano afirmou:

Há poucos dias pedi ao Saldanha da Gama autorização para o meu amigo Raul Pompéia copiar o retrato de Barreto de Menezes, que V. Ex deseja e que provavelmente irá até o fim do mês, e o Saldanha acedeu prontamente. O mesmo faz quando se trata de coisa para mim, mas é tratar dos Materiais e achegas e o homem negar pão e água. (CA-RB 08.02.1887)

Esta preocupação com a publicação dos documentos era, para Capistrano, uma necessidade que comporia a própria identidade do historiador, composta por dois elementos distintos, mas correlatos: o ofício do historiador e 
seu produto, o discurso histórico. ${ }^{27} \mathrm{~A}$ ansiedade com a publicação dos documentos, a solicitação para que o Barão compusesse e editasse, o mais rápido possível, seus textos e as críticas a Varnhagen demonstram o quanto a documentação tinha um papel central na escrita da história.

Em carta ao Barão, Capistrano comentou:

Ainda não pude verificar onde Varnhagen colheu os esclarecimentos a respeito do assalto inglês na Bahia. Não figuram na primeira edição. Provavelmente encontrou os documentos em Simancas, onde deviam estar, se ele não os tirou, porque hoje cheguei à desoladora convicção de que o nosso ilustre historiador roubava papéis. (CA-RB 30.03.1887)

As duas cartas estão ligadas pelo desconhecimento, segundo Capistrano de Abreu, tanto de Saldanha da Gama quanto de Varnhagen das regras que delimitavam o fazer moderno do conhecimento histórico. "Roubar papéis" delineava a apropriação privada do documento e expressava a ausência do cumprimento de uma norma obrigatória a todos os pesquisadores, tornar públicas as fontes de sua pesquisa. Porém, em estudo recente, Temístocles César conferiu complexidade a essa afirmação veemente de Capistrano. A imparcialidade na obra do Visconde de Porto Seguro era uma questão mais ampla, que não se restringia unicamente a uma questão de método, mas que estava ligada, principalmente, a marcas de subjetividade que tinham como limite o próprio Varnhagen. ${ }^{28}$

Retornando a Capistrano, seria impossível, sem a documentação, escrever a História do Brasil. Talvez por isso tenha se tornado um especialista nos arquivos estrangeiros, principalmente naqueles que tinham manuscritos referentes ao nosso período colonial. Enquanto pesquisador, tencionou construir um sólido corpo documental que possibilitasse a escrita da História do Brasil. Dessa maneira, a solicitação de manuscritos ao Barão do Rio Branco possuía uma questão ordenadora de toda a procura, qual seja, a acumulação dos manuscritos que depois seriam convertidos em documentos e que seguiam as regras determinadas pelo método histórico. Apesar da intenção deste texto não ser examinar, de maneira detida, as relações entre os procedimentos metódicos e a escrita histórica - questão que demandaria o recurso muito mais amplo a toda obra de Capistrano de $\mathrm{Abreu}^{29}$ —, a proximidade no tratamento das fontes não negava a diferenciação ocorrida no uso político da história, principalmente ao enfocarmos as decisões de Rio Branco.

Enfim, é interessante notar que, apesar de não contarmos com as cartas enviadas pelo Barão do Rio Branco ao seu interlocutor Capistrano de Abreu, é possível interpretar como o conhecimento histórico apresentava diferencia- 
da importância para cada um deles. Para o Barão do Rio Branco havia uma razão de ordem política para o estudo da história: o uso do passado articulava-se à necessidade de legitimação de seus argumentos em suas contendas diplomáticas, visto que o conhecimento do passado adquiria um aspecto pragmático, enquanto parte indissociável do realismo presente em sua ação política, apesar dos traços racionalistas ou grotianos. Para Capistrano de Abreu, o conhecimento histórico estava ligado ao conceito de "formação", um termo que indica incompletude na expressão do tempo da nação e, simultaneamente, aponta o caráter pedagógico das investigações históricas do autor; a maneira como equilibrava a exigência de imparcialidade e de posicionamento intelectual.

Entre muitas tangências e outras tantas dissonâncias, Capistrano de Abreu e o Barão do Rio Branco construíram, através do intercâmbio epistolar, um espaço de circulação de idéias em que é possível, através das redes e práticas de sociabilidade intelectual, caracterizar opiniões e categorias compartilhadas pelos indivíduos. Nesse sentido, o envio de cartas de Capistrano ao Barão, que durou mais de quinze anos, suscita que, através da escrita de um intelectual, aspectos da trajetória de outro possam ser conhecidos, pensados, inferidos. Se a lacuna documental impede a completude da análise da troca epistolar, o envio das cartas de Capistrano ao Barão possibilita um ângulo particular de visão de temas que mobilizaram dois intelectuais brasileiros, de perfis tão distintos, separados pelas águas do Atlântico, no apagar das luzes do século XIX.

\section{NOTAS}

${ }^{1}$ Carta de Capistrano de Abreu para o Barão do Rio Branco (22.12.1886). ABREU, Capistrano de. In: RODRIGUES, José Honório (Org.) Correspondência, v.1, p.105. Todas as outras cartas dessa referida troca epistolar serão citadas no corpo do texto com a referência CA-RB, visto que constam na obra organizada por José Honório Rodrigues.

${ }^{2}$ Ver: FOUCAULT, Michel. A escrita de si. In: O que é um autor? 4.ed. Lisboa: Passagens/Vega, 2000. p.18-57. Ver, também: GOMES, Ângela de Castro. Escrita de si, escrita da história. In: Escrita de si, escrita da história. Rio de Janeiro: Ed. FGV, 2005. p.7-24.

${ }^{3}$ Sobre a importância do estudo histórico como base de legitimação para assuntos políticos e diplomáticos ver: GOMES, Ângela de Castro. História e historiadores: a política cultural do Estado Novo. Rio de Janeiro: Ed. FGV, 1996.

${ }^{4}$ Para uma análise detida deste ponto, ver: PEREIRA, Daniel Mesquita. Descobrimentos de Capistrano: a história do Brasil "a grandes traços e largas malhas". Tese (Doutorado) Departamento de História, PUC-Rio. Rio de Janeiro, 2002. A trajetória de Capistrano tam- 
bém é analisada em FELIPPE, Eduardo Ferraz. Formação e dissolução: a inacabada história de Capistrano de Abreu. Dissertação (Mestrado) - Departamento de História, PUC-Rio. Rio de Janeiro, 2007.

${ }^{5}$ Nicolau Sevcenko, em livro clássico, caracterizou a importância do círculo construído pelo Barão do Rio Branco e que tinha nomes como Machado de Assis e Euclides da Cunha, entre outros. SEVCENKO, Nicolau. Literatura como missão: tensões sociais e criação cultural na Primeira República. 3.ed. São Paulo: Brasiliense, 1989. p.138-145.

${ }^{6}$ Acerca da construção da memória intelectual de Capistrano de Abreu, ver: GONTIJO, Rebeca. O velho vaqueano: Capistrano de Abreu, da historiografia ao historiador. Tese (Doutorado) - Universidade Federal Fluminense. Niterói, 2006. O conjunto da correspondência de Capistrano de Abreu foi analisado por AMED, Fernando. As cartas de Capistrano de Abreu: sociabilidade e vida literária na belle époque carioca. São Paulo: Alameda, 2006.

${ }^{7}$ VENTURA, Roberto: Estilo tropical: história cultural e polêmicas literárias no Brasil. São Paulo: Companhia das Letras, 1991.

${ }^{8}$ Patrícia Hansen, ao examinar o caso de João Ribeiro, pondera de maneira precisa acerca da fluidez existente entre os campos de conhecimento e o contato íntimo entre história e geografia. Ver: HANSEN, Patrícia. Feições \& fisionomia: a história do Brasil de João Ribeiro. Rio de Janeiro: Access, 2000.

${ }^{9}$ GOMES, Ângela de Castro. História e historiadores: a política cultural do Estado Novo. Rio de Janeiro: Ed. FGV, 1996. p.208-215.

${ }^{10}$ Essa troca epistolar foi analisada por GONTIJO, Rebeca. A reta e o círculo: amizade, projeto intelectual e construção identitária nas cartas de Capistrano de Abreu a João Lúcio Azevedo (1916-1927). Trajetos, Revista UFC, v.3, n.5, p.101-128, 2004.

${ }^{11}$ Acerca da correspondência como "lugar de sociabilidade" ver: GOMES, Ângela de Castro. Introdução. In: Em família: a correspondência de Oliveira Lima e Gilberto Freire. Campinas (SP): Mercado de Letras, 2005. p.7-43.

${ }^{12}$ ABREU, Capistrano de. Gravetos de História Pátria (19.10.1880). In: Ensaios e estudos, $4^{a}$ Série. Rio de Janeiro: Civilização Brasileira, 1977. p.157.

${ }^{13}$ RICUPERO, Rubens. Rio Branco: o Brasil no mundo. Rio de Janeiro: Contraponto, 2000. p.27-51.

${ }^{14}$ Ratzel foi um dos pioneiros da antropogeografia, responsável, no ambiente alemão, por relativizar o determinismo do meio que vigorava enquanto proposição teórica na ambiência acadêmica mundial. Ver: MORAES, Antonio Carlos Robert. Introdução. In:

(Org.) Ratzel. Coleção Grandes Cientistas Sociais. São Paulo: Ática, 1990. p.8-45. Assim como SEMPLE, Ellen Churchill. Influences of geographic environment on the basis of Ratzel's system of anthropogeography. New York: H. Holt, c.1911.

${ }^{15}$ PAGDEN, Anthony. European encounters with the New World: from Renaissance to Romanticism. New Haven: Yale University Press, 1994. p.10.

${ }^{16}$ ABREU, J. C. Caminhos antigos e povoamento do Brasil. In: ABREU, C. Caminhos antigos e povoamento do Brasil. Rio de Janeiro: Civilização Brasileira, 1977. p.42.

${ }^{17}$ Acerca da noção de ilha-Brasil, o espaço mítico em que se inscrevia a formação do terri- 
tório como um importante eixo estruturador da história brasileira, ver: MAGNOLI, Demétrio. O corpo da Pátria - imaginação geográfica e política externa no Brasil. São Paulo: Ed. Unesp, 2007.

${ }^{18}$ A principal base teórica para os princípios racionalistas é fruto da argumentação do filósofo holandês Hugo Grotius (1583-1645), tida como ponto de partida para o desenvolvimento de uma tradição do racionalismo na política internacional. JUNIOR, Gustavo Sénéchal. Entre poder e direito: a tradição grotiana na política externa brasileira. Brasília: Funag, 2005. p.13-18.

${ }^{19}$ RICUPERO, Rubens. Um personagem da República. In: ARAÚJO, João Hermes Pereira de (Org.) José Maria da Silva Paranhos: uma biografia fotográfica. Rio de Janeiro: Ed. UFRJ, 2003. p.15-40.

${ }^{20}$ Carta de Capistrano para Domício Gama (11.11.1916). In: Correspondência de Capistrano de Abreu, v.1. Rio de Janeiro: Civilização Brasileira, 1977. p.262.

${ }^{21}$ PRADO, Eduardo. A ilusão americana. 5.ed. São Paulo: Ibrasa, 1980. p.17-30.

${ }^{22}$ GRAFTON, Anthony. As origens trágicas da erudição: pequeno tratado sobre a nota de rodapé. Campinas (SP): Papirus, 1998.

${ }^{23}$ Os principais autores que tematizaram este ponto foram: ARAÚJO, Ricardo Benzaquen de. Ronda noturna: narrativa, crítica e verdade em Capistrano de Abreu. Revista Estudos Históricos, v.1, p.28-54, 1988; e FALCON, Francisco José Calazans. As noções de nação e de moderno nos textos de Capistrano de Abreu. Ensaios e estudos $4^{\text {a }}$ série. Acervo, Revista do Arquivo Nacional, Rio de Janeiro, n.9, p.7-25, 1999.

${ }^{24}$ Carta de Capistrano de Abreu para Guilherme Studart [20.04.1904]. In: Correspondência..., v.1, p.166.

${ }^{25}$ CERTEAU, Michel de. A operação historiográfica. In: A escrita da história. Rio de Janeiro: Forense-Universitária, 1982. p.34-78.

${ }^{26}$ FOUCAULT, Michel. Arqueologia do saber. Petrópolis (RJ): Vozes, 1972. p.161.

${ }^{27}$ FALCON, Francisco José. A identidade do historiador. Revista Estudos Históricos, Dossiê Historiografia, n.17, p.4-19, 1996.

${ }^{28}$ CÉZAR, Temístocles. Em nome do pai, mas não do patriarca: ensaio sobre os limites da imparcialidade na obra de Varnhagen. Revista História, v.24, n.2, 2005. Versão online.

${ }^{29}$ Essa questão foi examinada através da hipótese de que os dispositivos da crítica documental, ao mesmo tempo em que conferem as marcas de credibilidade ao texto histórico, também impõem limites incontornáveis a sua construção, por OLIVEIRA, Maria da Glória de. Crítica, método e escrita da história em João Capistrano de Abreu (1853-1927). Dissertação (Mestrado) — UFRGS. Porto Alegre, 2006. Versão online.

Artigo recebido em fevereiro de 2008. Aprovado em setembro de 2008. 